\title{
Estimating the Year Each State in the United States Will Achieve the World Health Organization's Elimination Targets for Hepatitis C
}

\author{
Mark Sulkowski · Wei-Han Cheng · Steven Marx • Yuri Sanchez Gonzalez • \\ John Strezewski $\cdot$ Nancy Reau (D)
}

Received: July 28, 2020 / Accepted: October 14, 2020 / Published online: November 3, 2020

(C) The Author(s) 2020

\begin{abstract}
Introduction: Although hepatitis $\mathrm{C}$ virus (HCV) infection remains a major clinical, economic, and societal burden, the development of curative antiviral therapy may accelerate the path toward elimination. This analysis assessed the progress of United States (US) states towards achieving the World Health Organization's (WHO) $2030 \mathrm{HCV}$ elimination targets for incidence, mortality, diagnosis, and treatment.

Methods: A previously published Markov model was used to simulate HCV progression over time to estimate the path to HCV elimination in each state based on prevalence, annual treatment, and diagnosis inputs from two large US laboratory datasets from January 2013 to December 2017. State-specific fibrosis
\end{abstract}

Electronic supplementary material The online

version of this article (https://doi.org/10.1007/s12325020-01535-3) contains supplementary material, which is available to authorized users.

M. Sulkowski

Johns Hopkins University School of Medicine, Baltimore, MD, USA

W.-H. Cheng · S. Marx · Y. Sanchez Gonzalez . J. Strezewski

Health Economics and Outcomes Research, AbbVie Inc., North Chicago, IL, USA

N. Reau $(\bowtie)$

Rush University Medical Center, Chicago, IL, USA

e-mail: Nancy_Reau@rush.edu stage restrictions on treatment in 2017 were included. The model estimated the year individual states would meet the WHO targets for diagnosing $90 \%$ of the $\mathrm{HCV}$-infected population, treating $80 \%$ of the eligible population, reducing new $\mathrm{HCV}$ infections by $80 \%$, and reducing HCV-related deaths by $65 \%$. The minimum number of annual treatments needed between 2020 and 2030 to achieve the WHO treatment target was also calculated.

Results: Overall, the USA is projected to achieve HCV elimination by 2037, with individual targets related to mortality, diagnosis, treatment, and incidence being achieved by 2020, 2027, 2033, and 2037, respectively. Three states (Connecticut, South Carolina, and Washington) are on track to meet all four elimination targets by 2030, and 18 states are not expected to meet these targets before 2040 . The estimated annual number of treatments required during 2020-2030 nationally to reach the WHO treatment target is 173,514 .

Conclusion: With the exception of three states, the USA is not on target to meet the WHO 2030 elimination targets and $35 \%$ are off track by 10 years or more. Strategies must be implemented to reduce overall prevalence by preventing new infections, increasing rates of screening, improving linkage to care, and implementing unfettered access to curative therapy. 
Keywords: Elimination; $\quad$ Epidemiology;

Hepatitis C; Infectious disease; Prevalence

\section{DIGITAL FEATURES}

This article is published with digital features, including a summary slide and infographic, to facilitate understanding of the article. To view digital features for this article go to https://doi. org/10.6084/m9.figshare.13042667. 


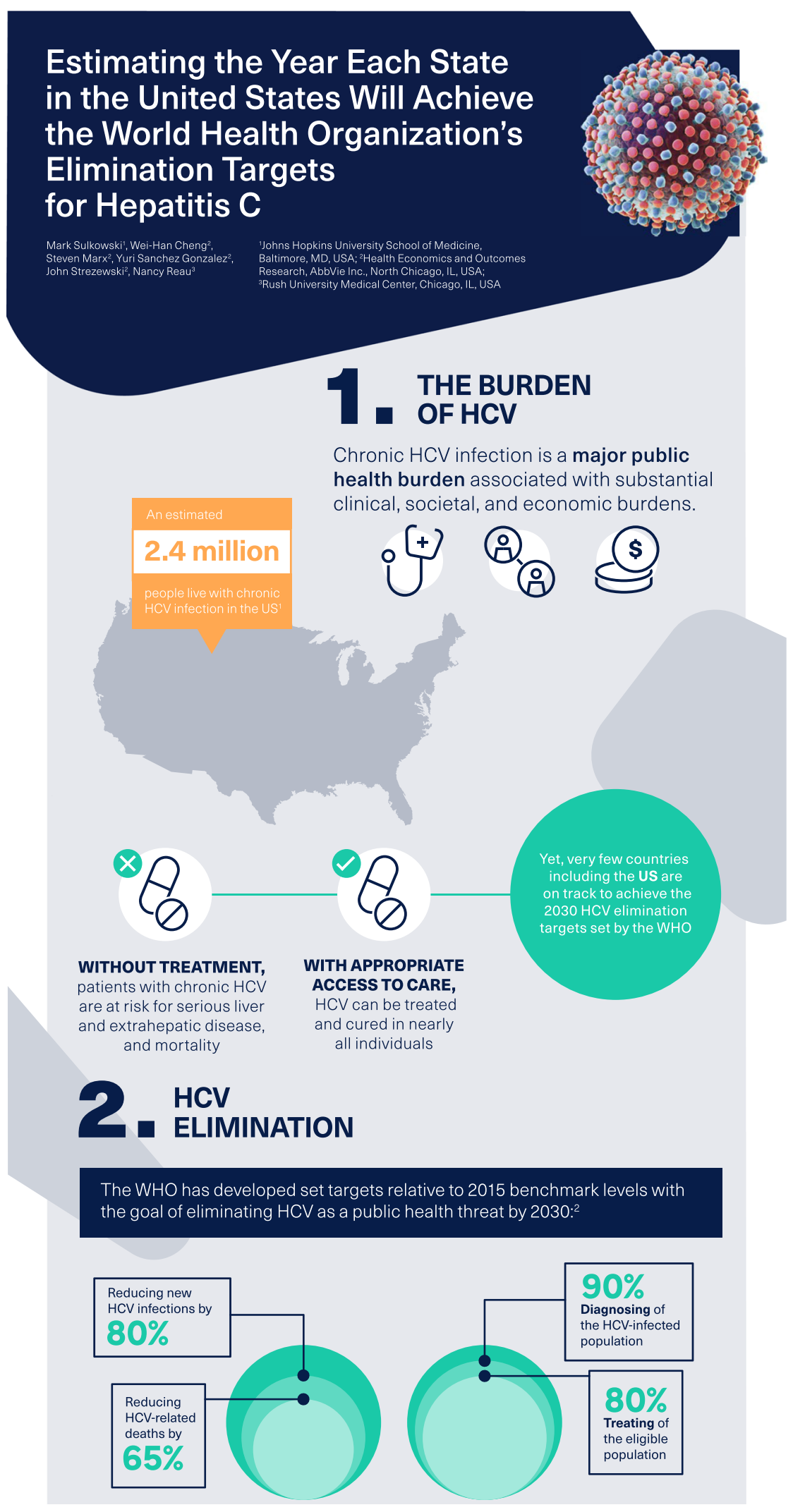




\section{THIS STUDY ASSESSED THE PROGRESS TOWARDS HCV - ELIMINATION IN THE US}

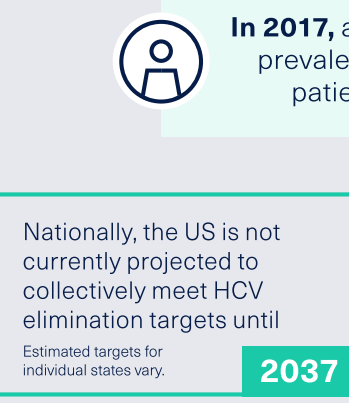

Estimated targets for

\section{7 \\ (2037}

individual states vary.

In 2017, an estimated total prevalence of 3 million patients had HCV
The target for diagnosis is projected to be achieved by

2027

Less than
$50 \%$ were
diagnosed

Year $\leq 2030 \quad 2031-2035 \quad 2036-2040 \quad 2041-2049 \quad \leq 2050$


INCIDENCE TREATMENT
by 2037 by 2033

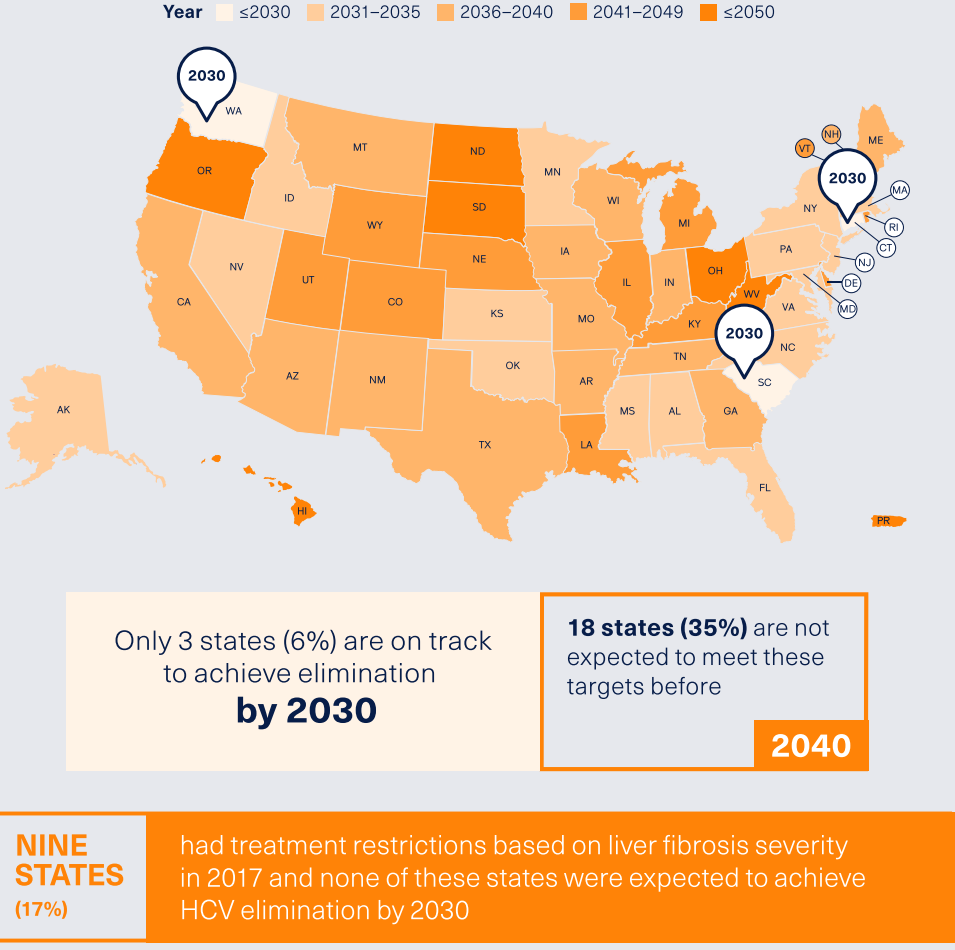

AN ANNUAL ESTIMATION OF 173,514 TREATMENTS are required nationally during 2020-2030 to reach the treatment target for HCV elimination by 2030

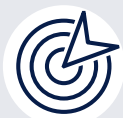




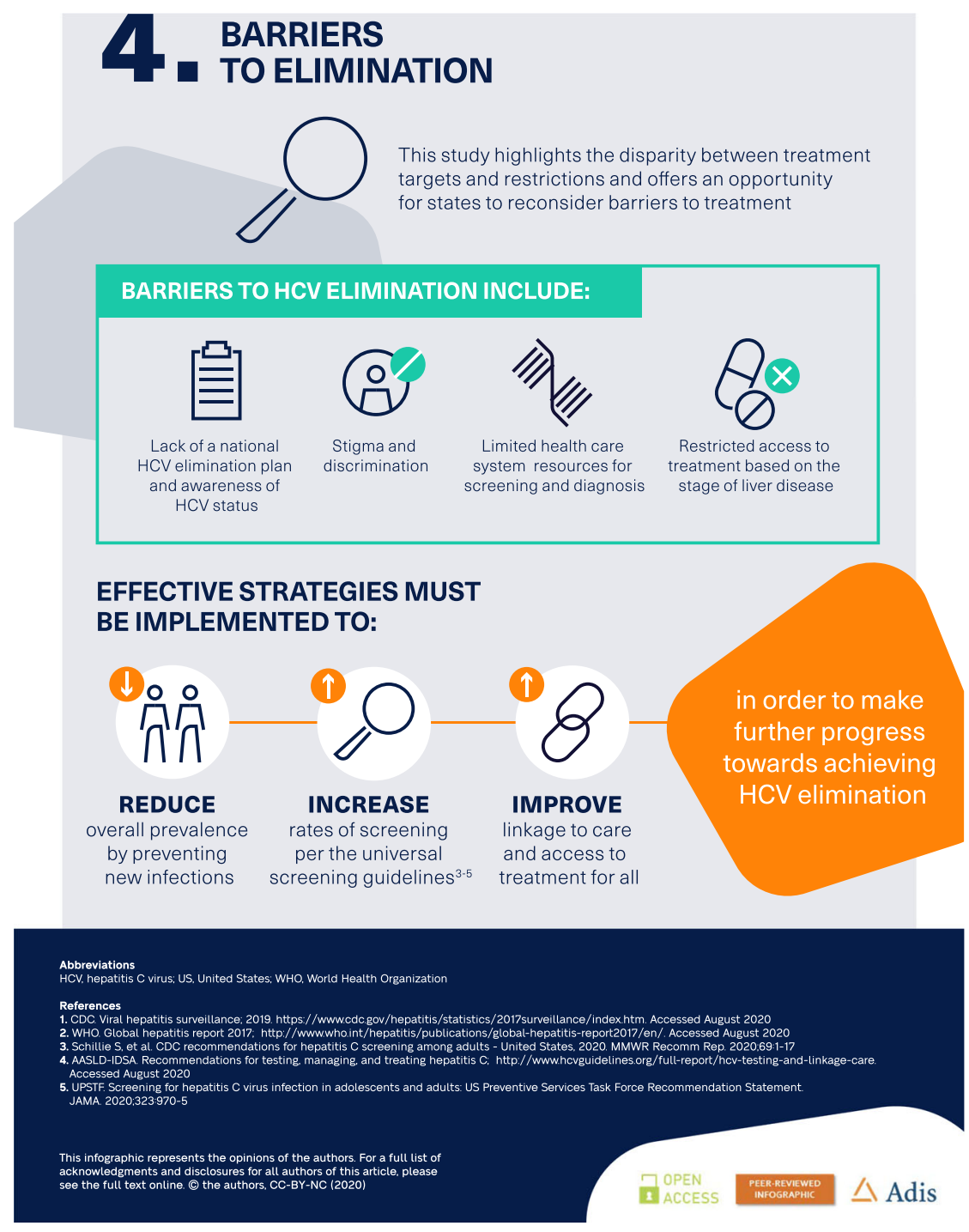

\section{INTRODUCTION}

Viral hepatitis $\mathrm{C}$ is one of the most common blood-borne infectious diseases and is associated with a substantial clinical, societal, and economic burden with over 70 million individuals affected globally [1, 2], including an estimated 2.4 million people living with chronic hepatitis $C$ virus (HCV) infection in the USA [3]. This burden is especially high among younger people who inject drugs, with up to $70 \%$ of new HCV infections occurring among people who inject drugs in the USA [4].
The number of new cases of HCV infection among this demographic has increased from 10,000 annually in 2005 to 40,000 annually in 2016 [5]. Owing to these increases in HCV infections among younger individuals, the Centers for Disease Control and Prevention (CDC), the US Preventive Services Task Force (USPTF), and the American Association for the Study of Liver Diseases-Infectious Diseases Society of America (AASLD-IDSA) have all endorsed universal screening for HCV in adults ( $\geq 18$ years of age) [6-8]. Chronic HCV infection 
is characterized by progressive liver fibrosis and the potential development of cirrhosis and hepatocellular carcinoma (HCC) $[9,10]$. In addition to advanced liver disease, chronic HCV infection has been associated with many extrahepatic manifestations that involve several organ systems $[9,11]$. As a result, untreated $\mathrm{HCV}$ infection is a leading cause of morbidity and mortality [10]. While mortality from other top infectious diseases including human immunodeficiency virus (HIV), malaria, and tuberculosis is declining, mortality caused by viral hepatitis is increasing. The number of global deaths from hepatitis was 1.34 million in 2015 [10] which exceeds the number of HIVrelated annual deaths in 2017 (0.95 million) [12]. Recently approved pangenotypic directacting antiviral (DAA) regimens have demonstrated high rates of sustained virologic response and good tolerability compared with former interferon-based therapies, and have substantially shortened treatment durations to 8 to 12 weeks of oral therapy [13]. Therefore, with access and linkage to care, HCV can be successfully treated and cured in most individuals, which is expected to yield substantial reductions in estimated future healthcare costs (\$3.3 billion), morbidity, and mortality (an estimated 320,000 lives saved) in the USA [14].

The World Health Organization (WHO), through the Global Health Sector Strategy on Viral Hepatitis 2016-2021, has called for the elimination of viral hepatitis as a significant public health threat by 2030 [15]. To achieve the goal of HCV elimination, the WHO has established a series of HCV elimination targets related to increases in diagnosis and treatment and reduction in incidence and $\mathrm{HCV}$-related death [15]. With the WHO target year of elimination only 10 years away, global progress towards HCV elimination has been limited. A recent study has shown that many high-income countries are not expected to achieve elimination before 2050, including the USA [16]. The identification of states not on track to meet elimination targets allows for modification of screening, assessment, and linkage of care; therefore, the objective of this study was to assess the progress and timeline of US states towards achieving the $2030 \mathrm{HCV}$ elimination targets set by the WHO.

\section{METHODS}

\section{Markov Model}

A previously published Markov disease progression model $[1,16]$ was used and expanded to simulate $\mathrm{HCV}$ progression over time in all 50 US states, Washington, DC, and Puerto Rico (which will be referred to as "states" henceforward). The model was used to forecast the annual HCV-infected population, HCV-related deaths, and disease burden by HCV sequelae, including fibrosis, cirrhosis, decompensated cirrhosis, HCC, and liver-related deaths as a means of estimating the path to the elimination of HCV in each state. The annual disease progression rates and mortality rates for each disease state in the model were obtained from published literature and validation of modelled outcomes was previously published [17]. The model has been widely adopted for this purpose in multiple global countries and three individual US states to forecast HCV prevalence, and the details have been described in the literature $[16,18-23]$. The disease progression model tracks the sex- and age-structured HCV-infected population from incidence through all stages of liver disease [fibrosis (F0-F3 on the METAVIR scale), compensated cirrhosis, decompensated cirrhosis, HCC, and liver transplantation] to eventual death (all-cause or HCV-liver-related). The Markov model calculated the disease progression among the $\mathrm{HCV}$-infected population by age and sex beginning in 1950, accounting for the inflows of incidence cases, and the outflows of mortality and patients who were treated and cured year over year to 2050 .

Key HCV epidemiology data were generated as inputs for the model, including the historical prevalence of viremic $\mathrm{HCV}$ infection, the annual diagnosed cases among the HCVinfected population, and the antiviral treatment regimen (number of annual treatments). $\mathrm{HCV}$ prevalence data and number of treated patients in each state (Table S1 in the supplementary material) were estimated on the basis of the combined de-identified data from the two large US laboratory datasets. Identical datasets were requested from both laboratories over the 
period of 2013-2017. All individuals who had an HCV antibody test (used for HCV screening to assess exposure to HCV) and an HCV-RNA viral-load test (used to confirm current $\mathrm{HCV}$ infection) between January 1, 2013 and December 31, 2017 were included in this analysis. In this dataset, the HCV RNA+ population was defined as the total number of patients with a positive HCV RNA test in the selected year. A longitudinal methodology was applied to define the prevalence of chronic $\mathrm{HCV}$ infection based on continuous laboratory tests to assess eligibility and carry HCV-related results forward. A machine learning methodology was applied to predict the proportion of patients with active $\mathrm{HCV}(\mathrm{RNA}+)$ who were treated and cured in each year [24]. The total number of unique HCV RNA+ individuals from 2013 to 2017 who were not cured was calculated to represent the total number of patients with diagnosed HCV in the USA [25].

To estimate the real-world number of HCV viremic patients in the US population, a geographic area-specific utilization of the data from the laboratory companies was used to extrapolate the number of $\mathrm{HCV}$ RNA+ patients in our dataset. The overall HCV viremic population was defined as the total number of unique patients with a positive HCV RNA test recorded during 2013-2017. The total number of unique HCV RNA+ individuals from 2013 to 2017 who had not been cured was calculated to represent the noninstitutionalized population of $\mathrm{HCV}$ infected persons similar to the national representative sample from the published literature (National Health and Nutrition Examination Survey, NHANES) [26]. The extrapolated HCV RNA+ estimates can be interpreted as the total number of diagnosed $\mathrm{HCV}$ viremic patients in the USA. A $48 \%$ undiagnosed rate was assumed in the estimation of the overall number of HCVinfected patients in the USA up to 2017 [27]. The proportion of patients with active HCV $(\mathrm{RNA}+)$ who were treated in 2017 as estimated by the machine learning algorithm was then applied to calculate the annual number of treated patients among all diagnosed $\mathrm{HCV}$ viremic patients.

Incident $\mathrm{HCV}$ infections were calculated separately into historical and future years.
Previously described calibration procedures were used to calibrate historical incident cases to match the reported total viremic HCV prevalence for the overall population, as well as by sex and age group $[1,16]$. Afterwards, the sex and age distribution of new infections was backcalculated to match reported prevalence by sex and age, assuming that the sex and age distributions of the general and HCV-infected populations were the same on the state level as on the national level. Future incident cases of HCV infection were assumed to change at the same annual rate as chronic prevalent cases (F0 or overall), relative to 2017 benchmark levels. In states with treatment or reimbursement restrictions based on fibrosis stage, the annual rate of change in incident cases was linked to the annual rate of change in modeled FO prevalence. In states without treatment or reimbursement restrictions by fibrosis stage, the rate of change in HCV infection incident cases was based on the rate of change in all chronic prevalent cases [16].

The data on the annual number of treatments from 2015 to 2017 estimated from the two large laboratory datasets demonstrated a trending decrease in the number of patients treated each year. During this period, an approximate decrease of $4 \%$ in the annual number of treated patients was observed at the US national level. To reflect the trend in which the number of treated patients decreased between 2015 and 2017 in the actual observed data, we assumed the annual number of treated patients will continue to decrease at a $4 \%$ rate from 2020. State Medicaid restrictions on treatment in 2017 based on fibrosis stage were also considered to assess their role in delaying HCV elimination [28].

The primary clinical outcome of the model was the annual HCV-infected population by stage of liver disease, sex, and age, as well as the HCV-related deaths in the population. These outputs were used to estimate the path toward the elimination of $\mathrm{HCV}$ as a public health threat as per the WHO targets for 2030. 


\section{WHO Elimination Targets}

The WHO has identified four targets that need to be achieved to eliminate $\mathrm{HCV}$ as a public health threat by 2030 (relative to 2015 benchmark levels): (1) diagnosing $90 \%$ of the HCVinfected population; (2) treating $80 \%$ of the eligible population; (3) reducing new $\mathrm{HCV}$ infections by $80 \%$; and (4) reducing HCVrelated deaths by $65 \%$ [15]. Modeled forecasts on the annual HCV-infected population and the number of HCV-related deaths were used to estimate the year in which individual states would meet these four WHO elimination targets, assuming levels of HCV diagnosis and treatment in 2017 would remain constant through 2030 [15]. The projected year in which all four WHO elimination targets were collectively met was considered the year of $\mathrm{HCV}$ elimination. States that met all four goals before 2030 were considered on track for meeting the WHO elimination goal.

The study also estimated HCV prevalence for each state. On the basis of this information, the average minimum number of annual treatments necessary to achieve the WHO's treatment target over the course of 2020-2030 was calculated for every state to establish policy benchmarks for monitoring progress towards elimination annually. In line with the diagnosis coverage target, $90 \%$ of the chronic prevalent population was considered treatment eligible. The number of annual treatments necessary to meet the treatment target for elimination by 2030 was calculated by dividing $80 \%$ of the treatment-eligible population by 11 (the number of years between 2020 and 2030), net of cumulative treatments during the years 2015-2019.

\section{Compliance with Ethics Guidelines}

With permission, this modeling study utilized de-identified data from two US laboratory datasets. Because the data were de-identified, no ethics committee approval was required.

\section{RESULTS}

\section{Estimated Prevalence of Patients with HCV (HCV RNA+) in 2017}

The estimated prevalence of patients who are HCV RNA+ in 2017 is illustrated in Fig. S1 in the supplementary material. Overall, we estimated a total of 3,063,343 patients with HCV in the USA in 2017 with prevalence varying by state. The state with the highest prevalence of HCV infection was California $(507,181)$, and the state with the lowest prevalence was Hawaii (854).

\section{WHO Elimination Targets: Overall Year of Elimination}

The projected year for achieving all four WHO elimination targets (i.e., overall year of elimination) in individual states in the USA is shown in Fig. 1 and Table 1 . The projected year of overall elimination was soonest in Connecticut (2028) and latest in Hawaii, North Dakota, Ohio, Oregon, Puerto Rico, Rhode Island, South Dakota, and West Virginia (all beyond 2050). According to the national-level data, overall $\mathrm{HCV}$ elimination in the USA is projected to be achieved by 2037. Only three states (Connecticut, South Carolina, and Washington) are on track to meet all four elimination targets by 2030, and 18 states are not expected to meet these targets before 2040 .

\section{Year of Achieving Individual WHO Elimination Targets}

The years in which individual states are estimated to meet each of the four elimination targets related to incidence, liver-related death, diagnosis, and treatment are shown in Table 1. Of the four targets, reducing new HCV infections by $80 \%$ by the year 2030 is least likely to be achieved in individual states. Specifically, only three states (6\%; Connecticut, South Carolina, and Washington) are on track to reduce new HCV infections by $80 \%$ by 2030 . Less than one-third of states [16 states (31\%)] are on track to meet the goal of treating $80 \%$ of the eligible 


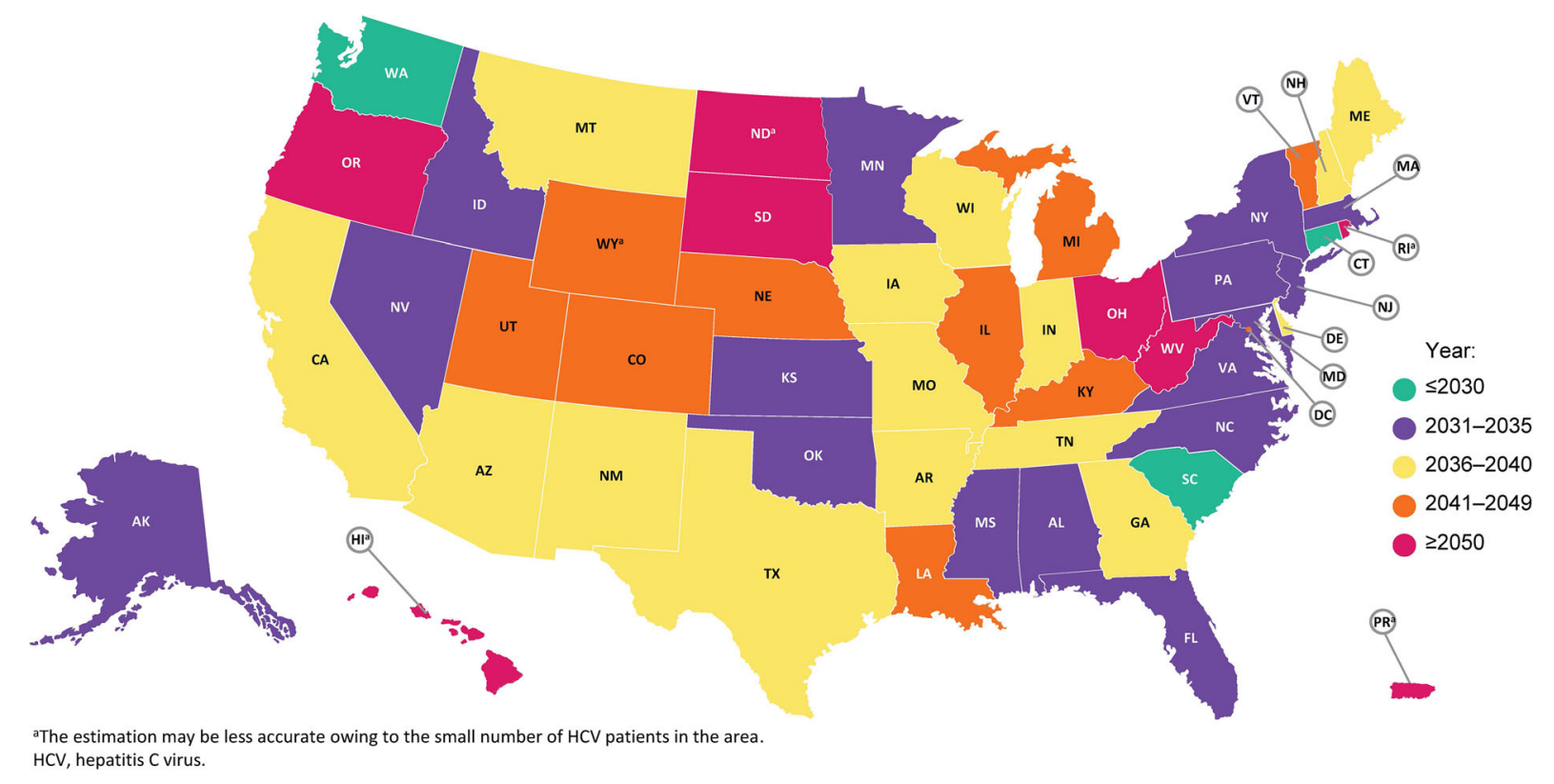

Fig. 1 Year of elimination. ${ }^{a}$ The estimation may be less accurate owing to the small number of patients with HCV in the area. HCV hepatitis $\mathrm{C}$ virus

population by 2030 . On the other hand, states are more likely to meet the WHO goals of diagnosing $90 \%$ of $\mathrm{HCV}$ infections by 2030 [45 states (87\%) are on track] and reducing HCV mortality by $65 \%$ by 2030 [ 47 states $(90 \%)$ are on track].

Similar trends for achieving the four individual goals were observed for the USA as a whole, with the estimated year of achieving each goal being 2020 for reducing HCV mortality by $65 \%, 2027$ for diagnosing more than $90 \%$ of the HCV population, 2033 for treating more than $80 \%$ of the eligible HCV population, and 2037 for reducing new HCV infections by $80 \%$.

Nine states $(17 \%)$ had treatment restrictions based on liver fibrosis severity in 2017 (Table 1) according to the reported state Medicaid restriction policy [28]. This included five states with restrictions based on F3 disease (Arkansas, Minnesota, Montana, South Dakota, and Texas), three states with restrictions by F2 disease (Alabama, Iowa, and Nebraska), and one state with restrictions based on F1 disease (Maryland). None of these states were expected to achieve HCV elimination by 2030 .

\section{Annual Number Needed to Treat to Meet 2030 Elimination Targets}

The estimated annual number of treatments required nationally during 2020-2030 to reach the treatment target for HCV elimination by 2030 is 173,514 . The estimated number needed to treat in each individual state is illustrated in Fig. 2 and listed for each state in Table 1. The estimated annual number of treatments ranged from 51 to 29,147 across the 52 states, with Hawaii having the lowest number needed to treat $(51)$ and California $(29,147)$ having the highest number needed to treat. Other states requiring at least 5000 patients to be treated to reach 2030 targets are (in decreasing order) Texas, Ohio, Florida, Pennsylvania, New York, Michigan, and Arizona. Thirteen states require at most 500 treatments between 2020 and 2030 to reach 2030 targets. These include (in decreasing order) Iowa, Nebraska, Montana, New Hampshire, Alaska, Idaho, South Dakota, Puerto Rico, Rhode Island, Wyoming, Vermont, North Dakota, and Hawaii. 
Table 1 Annual number needed to treat between 2020 and 2030 to achieve elimination by 2030

\begin{tabular}{|c|c|c|c|c|c|c|c|c|}
\hline \multirow[t]{2}{*}{ State } & \multicolumn{4}{|c|}{$\begin{array}{l}\text { Year in which individual WHO elimination } \\
\text { targets will be met }\end{array}$} & \multirow{2}{*}{$\begin{array}{l}\text { Year of } \\
\text { HCV } \\
\text { elimination }\end{array}$} & \multirow{2}{*}{$\begin{array}{l}\text { Annual number of } \\
\text { treatments from } \\
2020-2030 \text { to } \\
\text { achieve } 2030 \text { target }\end{array}$} & \multirow{2}{*}{$\begin{array}{l}\text { Treatment } \\
\text { restrictions } \\
\text { by fibrosis } \\
\text { stage in } 2017^{\mathrm{c}}\end{array}$} & \multirow{2}{*}{$\begin{array}{l}\text { NVHR } \\
2020 \\
\text { medicaid } \\
\text { access } \\
\text { grade }^{\text {d }}\end{array}$} \\
\hline & Incidence & $\begin{array}{l}\text { Liver- } \\
\text { related } \\
\text { death }\end{array}$ & Diagnosis & Treatment & & & & \\
\hline $\mathrm{AK}$ & 2033 & 2020 & 2024 & 2029 & 2033 & 380 & None & A- \\
\hline $\mathrm{AL}$ & 2034 & 2020 & 2025 & 2031 & 2034 & 1922 & $\mathrm{~F} 2$ & $\mathrm{D}+$ \\
\hline $\mathrm{AR}$ & 2039 & 2020 & 2025 & 2032 & 2039 & 2078 & F3 & $\mathrm{F}$ \\
\hline $\mathrm{AZ}$ & 2037 & 2020 & 2028 & 2034 & 2037 & 6322 & None & $\mathrm{C}+$ \\
\hline $\mathrm{CA}$ & 2039 & 2020 & 2030 & 2035 & 2039 & 29,147 & None & $A-$ \\
\hline $\mathrm{CO}$ & 2042 & 2021 & 2028 & 2039 & 2042 & 3551 & None & $A-$ \\
\hline $\mathrm{CT}$ & 2028 & 2019 & 2026 & 2026 & 2028 & 1639 & None & $\mathrm{A}+$ \\
\hline DC & 2039 & 2020 & 2043 & 2032 & 2043 & 749 & None & $B-$ \\
\hline $\mathrm{DE}$ & 2038 & 2021 & 2026 & 2034 & 2038 & 733 & None & $A-$ \\
\hline $\mathrm{FL}$ & 2031 & 2019 & 2028 & 2028 & 2031 & 13,350 & None & $\mathrm{B}+$ \\
\hline GA & 2039 & 2019 & 2026 & 2030 & 2039 & 3608 & None & $\mathrm{C}$ \\
\hline $\mathrm{HI}^{\mathrm{a}}$ & $>2050$ & 2049 & 2045 & $>2050$ & $>2050$ & 51 & None & B \\
\hline IA & 2036 & 2020 & 2026 & 2032 & 2036 & 443 & $\mathrm{~F} 2$ & $\mathrm{C}$ \\
\hline ID & 2034 & 2020 & 2025 & 2030 & 2034 & 313 & None & $\mathrm{A}-$ \\
\hline IL & 2044 & 2022 & 2027 & 2042 & 2044 & 3905 & None & $B-$ \\
\hline IN & 2040 & 2021 & 2025 & 2037 & 2040 & 2264 & None & $A-$ \\
\hline KS & 2031 & 2019 & 2027 & 2028 & 2031 & 766 & None & B \\
\hline KY & 2045 & 2025 & 2026 & 2045 & 2045 & 4505 & None & B \\
\hline LA & 2041 & 2021 & 2024 & 2038 & 2041 & 2469 & None & A \\
\hline MA & 2032 & 2019 & 2026 & 2029 & 2032 & 4760 & None & A \\
\hline $\mathrm{MD}$ & 2034 & 2020 & 2028 & 2031 & 2034 & 3648 & $\mathrm{~F} 1$ & B \\
\hline $\mathrm{ME}$ & 2037 & 2021 & 2031 & 2034 & 2037 & 629 & None & A- \\
\hline MI & 2042 & 2023 & 2026 & 2041 & 2042 & 7113 & None & A- \\
\hline MN & 2032 & 2019 & 2025 & 2027 & 2032 & 930 & F3 & $\mathrm{D}+$ \\
\hline $\mathrm{MO}$ & 2037 & 2020 & 2025 & 2034 & 2037 & 2584 & None & A \\
\hline MS & 2031 & 2019 & 2025 & 2028 & 2031 & 943 & None & $\mathrm{D}+$ \\
\hline MT & 2040 & 2021 & 2025 & 2035 & 2040 & 428 & F3 & $A-$ \\
\hline $\mathrm{NC}$ & 2032 & 2019 & 2026 & 2029 & 2032 & 4564 & None & B \\
\hline $\mathrm{ND}^{\mathrm{a}}$ & $>2050$ & 2045 & 2028 & $>2050$ & $>2050$ & 122 & None & $\mathrm{C}+$ \\
\hline $\mathrm{NE}$ & 2047 & 2025 & 2024 & 2047 & 2047 & 430 & F2 & $\mathrm{C}-$ \\
\hline
\end{tabular}


Table 1 continued

\begin{tabular}{|c|c|c|c|c|c|c|c|c|}
\hline \multirow[t]{2}{*}{ State } & \multicolumn{4}{|c|}{$\begin{array}{l}\text { Year in which individual WHO elimination } \\
\text { targets will be met }\end{array}$} & \multirow{2}{*}{$\begin{array}{l}\text { Year of } \\
\text { HCV } \\
\text { elimination }\end{array}$} & \multirow{2}{*}{$\begin{array}{l}\text { Annual number of } \\
\text { treatments from } \\
2020-2030 \text { to } \\
\text { achieve } 2030 \text { target }\end{array}$} & \multirow{2}{*}{$\begin{array}{l}\text { Treatment } \\
\text { restrictions } \\
\text { by fibrosis } \\
\text { stage in } 2017^{c}\end{array}$} & \multirow{2}{*}{$\begin{array}{l}\text { NVHR } \\
2020 \\
\text { medicaid } \\
\text { access } \\
\text { grade }^{\text {d }}\end{array}$} \\
\hline & Incidence & $\begin{array}{l}\text { Liver- } \\
\text { related } \\
\text { death }\end{array}$ & Diagnosis & Treatment & & & & \\
\hline $\mathrm{NH}$ & 2036 & 2020 & 2025 & 2032 & 2036 & 393 & None & $\mathrm{B}+$ \\
\hline $\mathrm{NJ}$ & 2033 & 2020 & 2031 & 2030 & 2033 & 3880 & None & $\mathrm{A}-$ \\
\hline NM & 2040 & 2021 & 2022 & 2036 & 2040 & 1347 & None & A \\
\hline $\mathrm{NV}$ & 2031 & 2019 & 2029 & 2028 & 2031 & 1124 & None & A- \\
\hline NY & 2034 & 2020 & 2035 & 2031 & 2035 & 7268 & None & A- \\
\hline $\mathrm{OH}$ & $>2050$ & 2040 & 2026 & $>2050$ & $>2050$ & 13,521 & None & $\mathrm{A}-$ \\
\hline $\mathrm{OK}$ & 2032 & 2019 & 2026 & 2029 & 2032 & 1957 & None & $\mathrm{C}$ \\
\hline OR & $>2050$ & 2027 & 2025 & $>2050$ & $>2050$ & 2322 & None & $\mathrm{A}-$ \\
\hline $\mathrm{PA}$ & 2035 & 2020 & 2029 & 2032 & 2035 & 7931 & None & A- \\
\hline $\mathrm{PR}^{\mathrm{a}}$ & $>2050$ & $>2050$ & $>2050$ & $>2050$ & $>2050$ & 205 & None & B \\
\hline $\mathrm{RI}^{\mathrm{a}}$ & $>2050$ & 2042 & 2025 & $>2050$ & $>2050$ & 166 & None & $\mathrm{A}-$ \\
\hline SC & 2030 & 2019 & 2026 & 2027 & 2030 & 1538 & None & $\mathrm{B}+$ \\
\hline SD & $>2050$ & 2034 & 2026 & $>2050$ & $>2050$ & 210 & F3 & $\mathrm{F}$ \\
\hline TN & 2040 & 2021 & 2026 & 2037 & 2040 & 3284 & None & $\mathrm{C}$ \\
\hline $\mathrm{TX}$ & 2039 & 2020 & 2027 & 2032 & 2039 & 13,621 & F3 & $\mathrm{D}+$ \\
\hline UT & 2042 & 2022 & 2026 & 2039 & 2042 & 585 & None & $\mathrm{C}-$ \\
\hline VA & 2033 & 2020 & 2028 & 2030 & 2033 & 3160 & None & $\mathrm{B}+$ \\
\hline VT & 2047 & 2025 & 2032 & 2043 & 2047 & 144 & None & $\mathrm{A}-$ \\
\hline WA & 2030 & 2019 & 2025 & 2027 & 2030 & 3133 & None & A \\
\hline WI & 2039 & 2021 & 2025 & 2035 & 2039 & 1171 & None & A \\
\hline WV & $>2050$ & 2029 & 2028 & $>2050$ & $>2050$ & 1774 & None & $\mathrm{B}-$ \\
\hline$W Y^{a}$ & 2041 & 2022 & 2028 & 2036 & 2041 & 148 & None & B \\
\hline
\end{tabular}

$H C V$ hepatitis C virus, NVHR National Viral Hepatitis Roundtable, WHO World Health Organization

a The estimation may be less accurate owing to the small number of patients with HCV in the area

b Elimination target thresholds: $80 \%$ reduction in incidence, $65 \%$ reduction in liver-related deaths, diagnosis of $90 \%$ of the HCV-infected population, and treating $80 \%$ of the eligible population

${ }^{c}$ Patients must reach a certain stage of fibrosis/liver disease prior to becoming eligible for treatment

d 2020 Medicaid Access Grades are provided by the National Viral Hepatitis Roundtable and based on discriminatory state Medicaid restrictions (i.e., fibrosis/liver disease treatment restrictions, sobriety treatment restrictions, and prescriber restrictions) [28] 


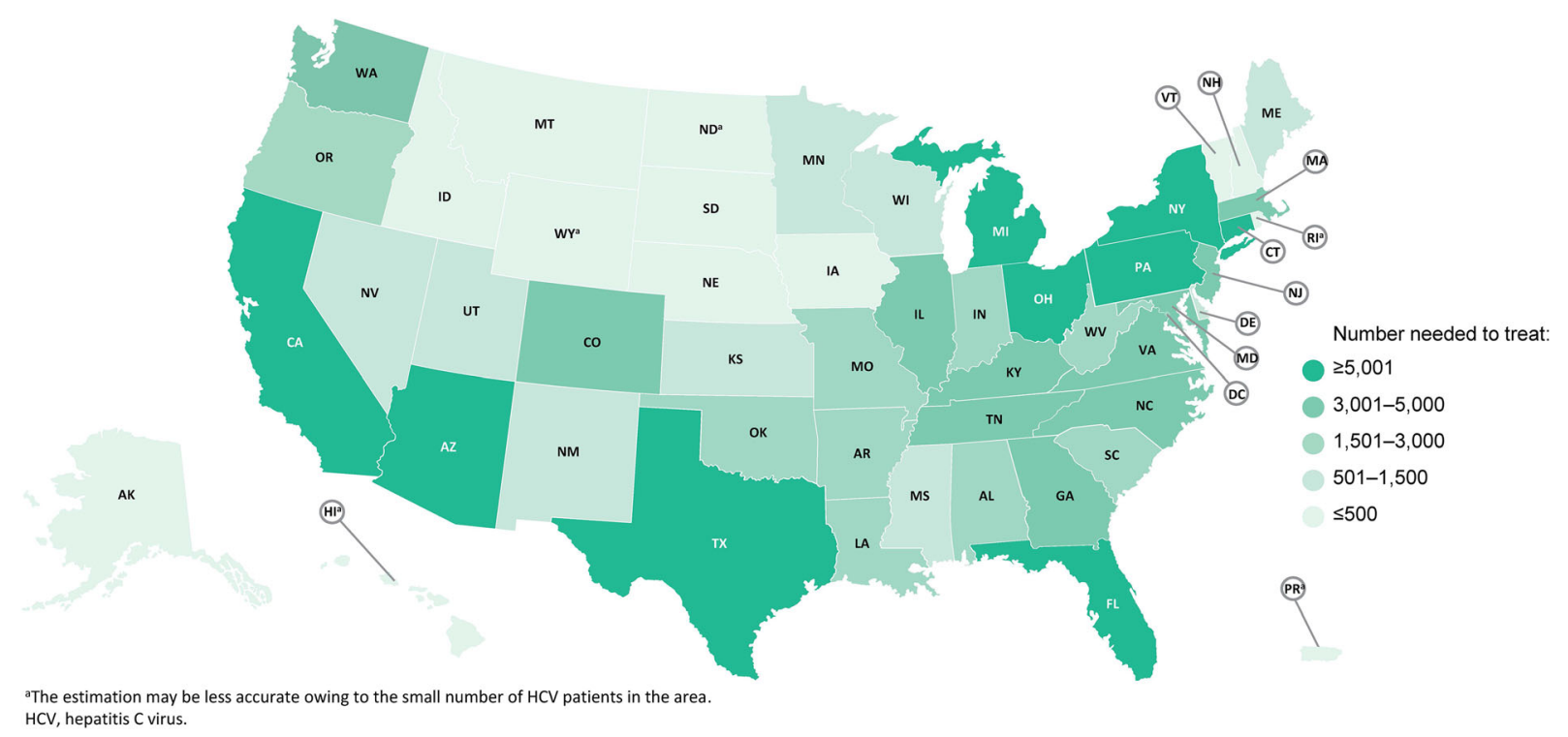

Fig. 2 Annual number needed to treat between 2020 and 2030. ${ }^{a}$ The estimation may be less accurate owing to the small number of patients with $\mathrm{HCV}$ in the area. $\mathrm{HCV}$ hepatitis $\mathrm{C}$ virus

\section{DISCUSSION}

Our study, which assessed the progress and timeline for US states to achieve the $2030 \mathrm{WHO}$ HCV elimination targets, suggests that the USA is not on track to meet these targets, as it is projected to achieve HCV elimination by 2037. Our analysis of states that are not projected to meet elimination targets allows for modifications in screening, assessment, and linkage to care. Comprehensive data similar to those used in this study that are regularly updated can be accessed by healthcare providers, policymakers, and payers to view the progress towards elimination in their states (accessed at MappingHepC.com) [25].

In a previous study that utilized similar methodologies and models to project the year of elimination, the estimated year of elimination in the USA was beyond 2050 [16]. The present analysis estimates an earlier year of $\mathrm{HCV}$ elimination based on the availability of prevalence, diagnosis, and treatment inputs from two large laboratory datasets. In contrast, the previous study was based on data derived from the Polaris Observatory, which relied on the best available published sources at the time of the study [16]. In the present study, we identified substantial differences between states for the estimated time to HCV elimination; these differences were driven by heterogeneous progress toward meeting the targets set by the WHO for $\mathrm{HCV}$ diagnosis, treatment, incidence, and mortality. When assessed at the state level, only $6 \%$ of states are on track to achieve overall HCV elimination by 2030 and $35 \%$ of states are not expected to meet these targets before 2040 . Additionally, we estimated the overall prevalence of patients with active HCV infection (RNA+ patients) in the USA to be approximately $3,063,343$, which is a higher estimate than previously reported from the NHANES data (2.3-2.4 million) [3, 26, 29]. The present study utilizes a dataset that combines two large de-identified US laboratory datasets from January 2013 through December 2017, while the NHANES data included data from 2013 to 2016 based on surveys extrapolated to the US population.

Among the individual WHO targets, the goal of reducing new incidences of $\mathrm{HCV}$ by $80 \%$ appears to be the most difficult to achieve. Only three states $(6 \%)$ are on track to meet this goal by 2030 , while 18 states (35\%) are estimated to achieve this goal in 2040 or later. These data indicate that increased efforts are needed to prioritize treatment for all patients with active 
HCV infection, particularly those at risk of transmitting $\mathrm{HCV}$ to others, including those who inject drugs and prisoners [3]. Meeting the WHO treatment target by 2030 is also behind schedule in most states (69\%) and the USA as a whole. The annual number needed to treat to meet the treatment target is 173,514 between 2020 and 2030. In five of eight states not projected to achieve elimination before 2050 (Hawaii, North Dakota, Rhode Island, Puerto Rico, and South Dakota), the annual number needed to treat is less than 500, suggesting the annual treatment benchmark in many of these states is low and achievable.

This study highlights the disparity between treatment targets and restrictions and offers an opportunity for states to reconsider barriers to treatment. The National Viral Hepatitis Roundtable (NVHR) report cards provide Medicaid access grades based on restrictions that still exist in each state which may be prohibitive to states meeting 2030 elimination targets [28]. Meeting the treatment target may be hampered by the persistence of treatment restrictions based on liver fibrosis severity in nine states (17\%); most of these states had Medicaid access grades of $\mathrm{C}$ to $\mathrm{F}$, apart from Maryland (B) and Montana (A-) [28]. Additional restrictions that may impact access to treatment, especially among high-risk groups, include sobriety restrictions in some states with 18 states requiring abstinence for at least 6 months, as well as limited access to healthcare and health insurance among the HCV-infected population [28]. Meeting the incidence and treatment targets will require the removal of these restrictions along with improved linkage to care efforts, especially among those with substance abuse disorders and poor social determinants of health. In support of increased screening, treatment, and improved linkage to care, the CDC, USPTF, and AASLD-IDSA have all provided updated guidance that supports universal screening recommendations. The universal screening guidelines indicate that all adults over the age of 18 years should be screened for HCV [6-8]. Additionally, AASLD-IDSA recommends that all patients with HCV infection should be treated, regardless of sobriety [7].
In contrast, the WHO elimination targets relating to diagnosis and reduction in mortality are on track for achievement in 2030 or earlier overall in the USA as well as in at least $87 \%$ of states. The 2019 National Virus Progress Report estimates the USA has met the 2020 goal to reduce the rate of HCV-related deaths [30]. While it is hard to compare different data sources, the model projections in our study align with that report as the model estimated the USA to meet the mortality reduction target in 2020. Mortality may be the easiest metric to meet by prioritizing (through restrictions) those patients with more advanced fibrosis, in which it would be the easiest to measure a decrease in mortality. Mortality may also be reduced in those patients with more comorbid conditions that are improved by viral eradication. However, it should be noted that the reductions in mortality cannot capture all-cause mortality (i.e., extrahepatic manifestations such as type 2 diabetes, end-stage renal disease, cardiovascular disease, or malignancy) that are also drivers of mortality but are not directly linked to $\mathrm{HCV}$.

There are key barriers that directly contribute to the limited progress in achieving HCV elimination targets. In particular, political will is considered crucial for providing sustained commitment and funding of HCV elimination strategies [16]. An example of a country in which political will exists is Australia, which has an estimated elimination target of 2026, which is earlier than the $2030 \mathrm{WHO}$ elimination target [16]. In the USA there is growing political will as evidenced by recent universal screening guidelines issued by the CDC and USPTF $[6,8]$ and the CDC has designated May as Hepatitis C Awareness Month to encourage screening of high-risk populations [31]. Sustained political will and policy changes at the federal and state level as well as funding for efforts to reduce $\mathrm{HCV}$ incidence and prevalence are required for HCV elimination. Examples of ways the USA could increase public health infrastructure to support elimination efforts include increased federal funding of national surveillance systems, expansion of access to and funding for syringe exchange programs and opioid agonist therapy, and removal of all restrictions to HCV treatment [31]. Treatment restrictions play a 
role since, in an effort to limit costs, some states have restricted access to treatment based on stage of liver disease [32]. The NVHR report cards highlight the states in which there is the greatest need to reduce treatment restrictions [28]. Stigma and discrimination against people with HCV can also impact access to HCV care [15]. Some states limit access to treatment for those with a history of illicit drug use or alcohol abuse [33]. This is compounded by the high lack of awareness of HCV status among those who inject drugs and the criminalization of drug use in most states [34]. The link between substance abuse and HCV is highlighted by the sharp increase in HCV infections among subgroups of the population who abuse or inject opioids [35]. Syringe exchange programs were previously shown to reduce the rates of $\mathrm{HCV}$ infection in New York City [36]. Limited public health and healthcare system resources, especially from government health insurance programs (i.e., Medicare, Medicaid) for screening and diagnosis and treatment, are also a significant barrier to treatment [14, 32]. Despite these barriers, there is evidence suggesting that full access strategies result in cost-savings and are associated with a reduction in the number of patients who progress to more advanced fibrosis or cirrhosis compared with more restrictive strategies $[32,37]$. The overall long-term social value generated from increasing access broadly is estimated to be substantial despite the increased short-term costs [38]. However, lifting treatment restrictions based on fibrosis staging or sobriety alone will not allow elimination targets to be met and may require improved linkage to care efforts to cure marginalized and disengaged patient populations.

There are several limitations to this analysis. First, the model assumes that every patient with $\mathrm{HCV}$ infection is at constant risk of transmitting $\mathrm{HCV}$, even though HCV transmission patterns and risk factors may vary regionally and depend on the size of the at-risk population in each state [39]. The size of the at-risk population in each state may depend on many factors, including the number of injection drug users, incarcerated individuals, and migrants from areas of high HCV prevalence. Another limitation is that HCV prevalence data prior to 2013 were not captured in our study. Therefore, information is not available for individuals with an HCV RNA+ test prior to this date without subsequent viral load tests. The model also assumes annual rates of treatment and diagnosis remain constant in the future, which may require increased efforts in screening and linkage to care to maintain. However, increased efforts in screening and linkage to care and initiating treatment in new patients may be hampered by the recent COVID-19 global pandemic. In light of the pandemic, HCV treaters have seen a reduction in face-to-face interactions and increases in telehealth visits in the USA and many healthcare providers have seen reductions in new prescriptions, which may be due to patients' unwillingness to initiate new therapy remotely and a lack of diagnostic testing that prevent diagnosis of new conditions, such as HCV infections [40]. It is anticipated that there may be a long-term impact of COVID-19 on healthcare provider engagement. Despite these challenges that healthcare providers face amid the COVID-19 pandemic, several major liver and hepatology societies recommend that providers should continue treatment of HCV-infected patients with COVID-19 and proceed with treatment in $\mathrm{HCV}$-infected patients without COVID-19 as clinically warranted [41-46]. Additionally, if there is an indication of a flare-up or reactivation of disease, therapy should be initiated in patients with COVID-19 and chronic HCV who are not already receiving treatment [41-43, 45, 46]. In patients with COVID-19 and elevated serum liver levels, other etiologies such as HCV should be considered, and these patients should be screened for viral hepatitis, which may highlight a need for increased screening and diagnosis in the USA $[41,43]$. Further, the model does not account for risk reduction due to harm-reduction programs or from the prioritized treatment of high-risk groups. The model also does not account for the impact of new treatment options or shortened treatment durations that may become available after 2017 . Finally, as with any forecast, the model results and the estimated year of elimination provide directional guidance on potential shortfalls in efforts to achieve HCV elimination and 
therefore may not exactly match the future trajectories observed in the real world.

\section{CONCLUSION}

This study highlights the limited progress towards HCV elimination in the USA and the need to increase HCV awareness. The estimates in this analysis suggest that the USA and most $(94 \%)$ of the individual states are not on track to achieve the WHO goal of HCV elimination by 2030. With 10 years remaining to meet these targets, it is important that strategies are implemented to increase rates of screening, linkage to care, and unfettered access to curative therapy.

\section{ACKNOWLEDGEMENTS}

We would like to acknowledge technical support provided by Homie Razavi and Ivane Gamkrelidze, employees of Center for Disease Analysis. AbbVie provided funding for this technical support.

Funding. Financial support for this study and the journal's Rapid Service Fee was provided by AbbVie. AbbVie participated in the interpretation of data, review, and approval of the publication. All authors contributed to the development of the publication and maintained control over the final content.

Medical Writing, Editorial, and Other Assistance. Medical writing services were provided by Brandy Menges of JK Associates, Inc. (a member of the Fishawack Group of Companies) and funded by AbbVie.

Authorship. All named authors meet the International Committee of Medical Journal Editors (ICMJE) criteria for authorship for this article, take responsibility for the integrity of the work as a whole, and have given their approval for this version to be published. No honoraria or payments were made for authorship.
Authorship Contributions. AbbVie participated in the interpretation of data, review, and approval of the publication. All authors contributed to the development of the publication and maintained control over the final content.

Prior Presentation. Data were presented in part at the European Association for the Study of the Liver's Digital International Liver Congress, August 27-29, 2020 and the Digestive Disease Week (DDW) 2020 digital platform.

Disclosures. Mark Sulkowski is an employee of Johns Hopkins University School of Medicine and reports grants from AbbVie, Gilead, Janssen, and the National Institutes of Health and personal fees from AbbVie, Gilead, Janssen, and Trek. Wei-Han Cheng, Steven Marx, Yuri Sanchez Gonzalez, and John Strezewski are employees of AbbVie and may own stocks and/ or stock options of the company. Nancy Reau is an employee of Rush University Medical Center and is a consultant for AbbVie, Gilead Sciences, Merck and Co, and Abbott. Her institution has received research support from Abbott, AbbVie, and Gilead Sciences.

Compliance with Ethics Guidelines. With permission, this modeling study utilized deidentified data from two US laboratory datasets. Because the data were de-identified, no ethics committee approval was required.

Data Availability. The datasets generated during and/or analyzed during the current study are available from the corresponding author on reasonable request.

Open Access. This article is licensed under a Creative Commons Attribution-NonCommercial 4.0 International License, which permits any non-commercial use, sharing, adaptation, distribution and reproduction in any medium or format, as long as you give appropriate credit to the original author(s) and the source, provide a link to the Creative Commons licence, and indicate if changes were made. The images or other third party material in this article are included in the article's Creative Commons licence, unless indicated otherwise in a credit 
line to the material. If material is not included in the article's Creative Commons licence and your intended use is not permitted by statutory regulation or exceeds the permitted use, you will need to obtain permission directly from the copyright holder. To view a copy of this licence, visit http://creativecommons.org/licenses/by$\mathrm{nc} / 4.0 /$.

\section{REFERENCES}

1. Polaris Observatory HCV Collaborators. Global prevalence and genotype distribution of hepatitis C virus infection in 2015: a modelling study. Lancet Gastroenterol Hepatol. 2017;2:161-76.

2. Reau N, Vekeman F, Wu E, Bao Y, Gonzalez YS. Prevalence and economic burden of extrahepatic manifestations of hepatitis $\mathrm{C}$ virus are underestimated but can be improved with therapy. Hepatol Commun. 2017;1:439-52.

3. CDC. Viral hepatitis surveillance; 2019. https:// www.cdc.gov/hepatitis/statistics/2017surveillance/ index.htm. Accessed March 14, 2020.

4. AASLD-IDSA. Management of acute HCV infection. Key populations: identification and management of HCV in people who inject drugs; https://www. hcvguidelines.org/unique-populations/pwid. Accessed June 1, 2020.

5. Jafri S-M, Gordon SC. Epidemiology of hepatitis C. Clin Liver Dis. 2018;12:140-2.

6. Schillie S, Wester C, Osborne M, Wesolowski L, Ryerson $\mathrm{AB}$. CDC recommendations for hepatitis $\mathrm{C}$ screening among adults-United States, 2020. MMWR Recomm Rep. 2020;69:1-17.

7. AASLD-IDSA. Recommendations for testing, managing, and treating hepatitis C. https://www. hcvguidelines.org/full-report/hcv-testing-andlinkage-care. Accessed 10 Apr 2020.

8. Force UPST. Screening for hepatitis $C$ virus infection in adolescents and adults: US Preventive Services Task Force Recommendation Statement. JAMA. 2020;323:970-5.

9. Chen SL, Morgan TR. The natural history of hepatitis C virus (HCV) infection. Int J Med Sci. 2006;3: 47-52.

10. WHO. Global hepatitis report 2017. https://www. who.int/hepatitis/publications/global-hepatitisreport2017/en/. Accessed 3 Jan 2020.
11. Cacoub P, Comarmond C, Domont F, Savey L, Desbois AC, Saadoun D. Extrahepatic manifestations of chronic hepatitis $\mathrm{C}$ virus infection. Ther Adv Infect Dis. 2016;3:3-14.

12. Frank TD, Carter A, Jahagirdar D, et al. Global, regional, and national incidence, prevalence, and mortality of HIV, 1980-2017, and forecasts to 2030, for 195 countries and territories: a systematic analysis for the Global Burden of Diseases, Injuries, and Risk Factors Study 2017. Lancet HIV. 2019;6: e831-59.

13. Sandmann L, Schulte B, Manns MP, Maasoumy B. Treatment of chronic hepatitis C: efficacy, side effects and complications. Visc Med. 2019;35: 161-70.

14. DHHS. National viral hepatitis action plan 2017-2020; 2020. https://www.hhs.gov/sites/ default/files/National\%20Viral\%20Hepatitis\% 20Action\%20Plan\%202017-2020.pdf. Accessed 14 Mar 2020.

15. WHO. Global health sector strategy on viral hepatitis 2016-2021; 2020. https://www.who.int/ hepatitis/strategy2016-2021/ghss-hep/en/. Accessed 14 Mar 2020.

16. Razavi H, Sanchez Gonzalez Y, Yuen C, Cornberg $\mathrm{M}$. Global timing of hepatitis $\mathrm{C}$ virus elimination in high-income countries. Liver Int. 2020;40:522-9.

17. Blach S, Zeuzem S, Manns M, et al. Global prevalence and genotype distribution of hepatitis $C$ virus infection in 2015: a modelling study. Lancet Gastroenterol Hepatol. 2017;2:161-76.

18. CDA. Colorado prevalence and incidence of hepatitis C virus infection: a modeling study; 2017. https://cdafound.org/content/Downloads/7.pdf. Accessed 14 Mar 2020.

19. CDA. Public health impact of a population-based approach to HCV treatment in New Mexico; 2019. https://cdafound.org/content/Downloads/Public\% 20health\%20impact\%20of\%20a\%20population-\% 20based $\% 20$ approach $\% 20$ to $\% 20 \mathrm{HCV} \%$ 20treatment\%20in\%20New\%20Mexico.pdf. Accessed 14 Mar 2020.

20. Soipe AI, Razavi H, Razavi-Shearer D, Galarraga O, Taylor LE, Marshall BDL. Chronic hepatitis C virus (HCV) burden in Rhode Island: modelling treatment scale-up and elimination. Epidemiol Infect. 2016;144:3376-86.

21. Won YK, Kang KS, Gonzalez YS, et al. A tool to measure the impact of inaction toward elimination of hepatitis C: a case study in Korea. PLoS One. 2020;15:e0232186. 
22. de Ledinghen V, Christophe B, Sanchez Y, Ruggeri F, Delaage P-H, Razavi H. SAT-259-achieving accelerated elimination of hepatitis $C$ virus infection by 2025: A case study in France. Poster presented at the International Liver Congress; 2019 April 10-14; Vienna.

23. Feld J, Rahal Y, Robert C, Sanchez Y, Razavi H. Anticipated timing of elimination of hepatitis $C$ virus in Canada's four most populous provinces. Poster presented at Canadian Liver Meeting; 2020 Feb 28-March 1; Montreal.

24. Chirikov VV, Marx SE, Manthena SR, Strezewski JP, Saab S. Development of a comprehensive dataset of hepatitis $C$ patients and examination of disease epidemiology in the United States, 2013-2016. Adv Ther. 2018;35:1087-102.

25. MappingHepC. Interactive map; 2020. https:// mappinghepc.com/maps. Accessed 14 Mar 2020.

26. Rosenberg ES, Rosenthal EM, Hall EW, et al. Prevalence of hepatitis $C$ virus infection in US states and the District of Columbia, 2013 to 2016. JAMA Network Open. 2018;1:e186371-e.

27. Chhatwal J, Chen Q, Bethea ED, Hur C, Spaulding AC, Kanwal F. The impact of direct-acting anti-virals on the hepatitis $C$ care cascade: identifying progress and gaps towards hepatitis $\mathrm{C}$ elimination in the United States. Aliment Pharmacol Ther. 2019;50:66-74.

28. NVHR, CHLPI. Hepatitis C: state of Medicaid access; 2020. https://stateofhepc.org/. Accessed 17 Mar 2020 .

29. Hofmeister MG, Rosenthal EM, Barker LK, et al. Estimating prevalence of hepatitis $C$ virus infection in the United States, 2013-2016. Hepatology. 2019;69:1020-31.

30. CDC. 2019 national virus hepatitis report; 2019. https://www.cdc.gov/hepatitis/policy/pdfs/

NationalProgressReport2019.pdf. Accessed 27 Mar 2020 .

31. Saab S, Le L, Saggi S, Sundaram V, Tong MJ. Toward the elimination of hepatitis $C$ in the United States. Hepatology. 2018;67:2449-59.

32. Chidi AP, Bryce CL, Donohue JM, et al. Economic and public health impacts of policies restricting access to hepatitis $C$ treatment for Medicaid patients. Value Health. 2016;19:326-34.

33. Tenner L, Melhado TV, Bobadilla R, Turner BJ, Morgan R. The cost of cure: barriers to access for hepatitis $\mathrm{C}$ virus treatment in South Texas. J Oncol Pract. 2019;15:61-3.
34. Durham DP, Skrip LA, Bruce RD, et al. The impact of enhanced screening and treatment on hepatitis C in the United States. Clin Infect Dis. 2016;62: 298-304.

35. Zibbell JE, Asher AK, Patel RC, et al. Increases in acute hepatitis $\mathrm{C}$ virus infection related to a growing opioid epidemic and associated injection drug use, United States, 2004 to 2014. Am J Public Health. 2018;108:175-81.

36. Jarlais DD, Perlis T, Arasteh K, et al. Reductions in hepatitis $C$ virus and HIV infections among injecting drug users in New York City, 1990-2001. AIDS. 2005;19(Suppl 3):S20-5.

37. Moreno GA, Wang A, Sánchez González Y, et al. Value of comprehensive HCV treatment among vulnerable, high-risk populations. Value Health. 2017;20:736-44.

38. Chou JW, Silverstein AR, Goldman DP. Short-term budget affordability of hepatitis $\mathrm{C}$ treatments for state Medicaid programs. BMC Health Serv Res. 2019;19:140.

39. Klevens RM, Hu DJ, Jiles R, Holmberg SD. Evolving epidemiology of hepatitis $C$ virus in the United States. Clin Infect Dis. 2012;55(Suppl 1):S3-9.

40. IQVIA. Monitoring the impact of COVID-19 on the pharmaceutical market (white paper). https://www. iqvia.com/library/white-papers/monitoring-theimpact-of-covid-19-on-the-pharmaceutical-market. Accessed 4 June 2020.

41. Lau G, Ward JW. Synthesis of liver associations recommendations for hepatology and liver transplant care during the COVID-19 pandemic. Clin Liver Dis. 2020;15:204-9.

42. Gregory C, Rino G, Richard G, et al. Clinical practice guidance for hepatology and liver transplant providers during the COVID-19 pandemic: APASL expert panel consensus recommendations. Hep Int. 2020;14:415-28.

43. Fix OK, Hameed B, Fontana RJ, et al. Clinical best practice advice for hepatology and liver transplant providers during the COVID-19 pandemic: AASLD expert panel consensus statement. Hepatology. 2020;72:287-304.

44. Wong GL-H, Wong VW-S, Thompson A, et al. Management of patients with liver derangement during the COVID-19 pandemic: an Asia-Pacific position statement. Lancet Gastroenterol Hepatol. 2020;5:776-87.

45. Boettler T, Newsome PN, Mondelli MU, et al. Care of patients with liver disease during the COVID-19 
pandemic: EASL-ESCMID position paper. JHEP Rep. 2020;2.
46. Boettler T, Marjot T, Newsome PN, et al. Impact of COVID-19 on the care of patients with liver disease: EASL-ESCMID position paper after 6 months of the pandemic. JHEP Rep. 2020;2. 